\title{
Progressive Insight into Tumor Promotion with Pro-inflammatory Cytokines
}

\author{
Hirota Fujiki ${ }^{1 *}$, Masami Suganuma ${ }^{2}$, Tatsuro Watanabe ${ }^{1}$, Eisaburo Sueoka $^{1}$ \\ ${ }^{1}$ Department of Clinical Laboratory Medicine, Faculty of Medicine, Saga University, Saga, Japan \\ ${ }^{2}$ Graduate School of Science and Engineering, Saitama University, Saitama, Japan
}

Received: October 29, 2015; Accepted: December 02, 2015; Published: December 05, 2015

*Corresponding author: Hirota Fujiki, Department of Clinical Laboratory Medicine, Faculty of Medicine, Saga University, 5-1-1 Nabeshima, Saga 849-8501, Japan, Tel: +81-92-292-0668; Fax: +81-92-292-0668; E-mail: uv4h-fjk@asahi-net.or.jp

\begin{abstract}
Absract
In 2013, we published a review article entitled "Tumor promoters: from chemicals to inflammatory proteins", describing that pro-inflammatory cytokines and chemokines in the cancer microenvironment induce tumor-promoting inflammation in human cancer development. We present here some significant topics based on our experiments: (i) The okadaic acid class of compounds, which are potent inhibitors of Protein Phosphatases 1 (PP1) and 2A (PP2A), showed a common mechanism of tumor promotion on mouse skin, in rat glandular stomach and in rat liver, (ii) Both 12-O-tetradecanoylphorbol-13-acetate (TPA) and okadaic acid commonly induced gene expressions of TNF- $\alpha$, IL- $1 \alpha$ and IL- $1 \beta$ on $\mathrm{TNF}^{+/+}$mouse skin, and these pro-inflammatory cytokines induced clonal growth of $v$-Ha-ras-transfected BALB/3T3 cells (Bhas 42), (iii) $H$. pylori genome contained a new TNF- $\alpha$-inducing protein (Tip $\alpha$ ) gene, and Tip $\alpha$ protein induced the Epithelial-Mesenchymal Transition (EMT) in human gastric cancer cells and (iv) Nucleolin on cell surface was identified as a receptor for Tip $\alpha$, emphasizing gastric tumor promotion and progression of $H$. pylori. Finally we discussed the broad roles of pro-inflammatory cytokines in tumor progression in relation to inflammasomes reported by other investigators.
\end{abstract} Tip $\alpha$

Keywords: Cytokine; Okadaic acid; Inflammasome; Nucleolin;

\section{Introduction}

Tumor promotion was intensively studied in the 1980s, and tumor promoters were found in various organs of rodents in two-stage carcinogenesis experiments [1]. However, tumor promotion is not accepted in clinical cancer development, because tumor promotion is thought to be mechanistically different from progression. In order to close up the relationship between tumor promotion and progression, a common mechanism of tumor promoters should be generalized in various organs. Based on our evidence that okadaic acid, an inhibitor of protein phosphatases 1 (PP1) and 2A (PP2A), is a potent tumor promoter on mouse skin initiated with 7,12-dimethylbenz [a] anthraxene (DMBA) as does 12-O-tetradecanoylphorbol-13-acetate (TPA), we intensively studied the mechanisms of okadaic acid in relation to TPA. The significant results of our experiments are as follows: Okadaic acid and TPA commonly induced gene expressions of TNF- $\alpha$, IL- $1 \alpha$ and
IL-1 $\beta$ on mouse skin $[2,3]$; The study of tumor promotion by both okadaic acid and TPA revealed that TNF- $\alpha$ is an essential tumor promoter in TNF- $\alpha$-deficient mouse skin initiated with DMBA [3]; Inhibitors of PP1 and PP2A induced tumor promotion on mouse skin, in rat glandular stomach and rat liver initiated with carcinogens [4]; TNF- $\alpha$, IL- $1 \alpha$ and IL-1 $\beta$ induced clonal growth of $v$-Ha-ras-transfected BALB/3T3 cells (Bhas 42) [3]; Treatment with tumor promoters commonly released TNF- $\alpha$ from target organs [5]. In light of our evidence showing that TNF- $\alpha$, IL- $1 \alpha$ and IL-1 $\beta$ act as endogenous tumor promoters and/or cancer mediators [6,7], we specifically found a TNF- $\alpha$-inducing protein (Tip $\alpha$ ) gene in H. pylori genome [8,9]. Tip $\alpha$ dimer bind to nucleolin on cell surface of human gastric cancer cells as a receptor [10], and are secreted in large quantities from $H$. pylori of gastric cancer patients [11]. The Epithelial-Mesenchymal Transition (EMT) was induced in human gastric cancer cells by Tip $\alpha$ [12]. The Tip $\alpha$ and nucleolin complex shows a strong link between tumor promotion and clinical cancer development. Since TNF- $\alpha$ and IL-1 are tumor-promoting cytokines, we discussed the role of inflammasome signaling for tumor promotion using apoptosisassociated speck-like protein containing a caspase recruitment domain (ASC)-KO and caspase (CASP)-1-KO mice reported by Campanelli's group [13].

\section{Methods}

The main experimental results are cited from our publications, and the relevant literatures reviewed in this article are screened from journals and PubMed.

\section{Results}

\section{Common mechanism of tumor promotion by inhibitors of PP1 and PP2A}

Tumor promoters of the okadaic acid class, which are all potent inhibitors of PP1 and PP2A, include okadaic acid, dinophysistoxin-1 (35-methylokadaic acid), calyculin A, microcystin-LR and nodularin [4]. Okadaic acid induced clonal growth of DMBA-initiated cells on CD-1 mouse skin as potently as did TPA. Okadaic acid also induced tumor promotion in male $\mathrm{SD}$ rat glandular stomach initiated with $N$-methyl- $N$ '-nitro- $N$ 
nitrosoguanidine. Microcystin-LR and nodularin were identified as new tumor promoters in rat liver initiated with diethyl nitrosamine. All of these results showed for the first time that inhibition of PP1 and PP2A is a common mechanism of tumor promotion in various organs $[4,7]$.

Human fibroblasts treated with both okadaic acid and TNF- $\alpha$ biochemically showed a similar phosphorylation pattern of over 140 proteins in two-dimensional gel electrophoresis, reported by Guy, et al. [14]. Next we found that treatment with okadaic acid, which acts as tumor promoter on mouse skin and rat glandular stomach, induced gene expressions of TNF- $\alpha$, IL- $1 \alpha$ and IL$1 \beta$ on mouse skin, and released TNF- $\alpha$ from KATO III cells of human stomach cancer cell line $[3,15]$. The i.p. administration of microcystin-LR and nodularin induced TNF- $\alpha$ gene expression in rat liver [5], and treatments with microcystin-LR and nodularin induced TNF- $\alpha$ release from rat hepatocytes into the medium, while TPA did not apparently release TNF- $\alpha$, nor showed tumorpromoting activity in rat liver [5]. To demonstrate the significance of TNF- $\alpha$ in tumor promotion, we conducted experiments with TNF- $\alpha$ deficient mice initiated with DMBA by topical applications of okadaic acid and TPA: Okadaic acid did not induce any tumors on skin of TNF- $\alpha^{-/-}$mice up to 19 weeks, but TNF- $\alpha^{+/+}$mice showed $100 \%$ of tumor incidence. In addition,TPA-treated TNF- $\alpha^{-/}$mice showed 2.8 in average number of tumors, compared with 11.8 for TNF- $\alpha^{+/+}$CD-1 mice [3]. Considering the residual tumor-promoting activity in TNF- $\alpha^{-/}$mice, we found significant expression of $I L-1 \alpha$ and $I L-1 \beta$ genes as additional inflammatory cytokines for tumor promotion in TNF- $\alpha^{-/}$mouse skin [3]. On the other hand, okadaic acid and TPA showed a similar potency of tumor promotion in IL-6\%and IL- $6^{+/+}$mice initiated with DMBA [15], suggesting that TNF- $\alpha$ and IL- 1 are essential tumor promoters, whereas IL-6 supplements functions of other cytokines.

\section{Carcinogenic role of TNF- $\alpha$ in cell transformation and tumorigenicity}

Human TNF- $\alpha$ at a concentration of $10 \mathrm{ng} / \mathrm{ml}(0.6 \mathrm{nM})$ induced 1.83 average No. of foci/dish, whereas okadaic acid at a concentration of $20 \mathrm{ng} / \mathrm{ml}(0.02 \mu \mathrm{M})$ showed 1.58 and TPA at a concentration of $300 \mathrm{ng} / \mathrm{ml}(0.5 \mu \mathrm{M}) 1.92 \mathrm{foci} /$ dish in BALB/3T3 cells initiated with 3-methylcholanthrene (MCA), respectively [6]. This is important to note that human TNF- $\alpha$ secreted from various cells has a more potent transforming activity than chemical tumor promoters. TNF- $\alpha$ also induced clonal growth in $\mathrm{v}$ - $\mathrm{Ha}$ ras-transfected BALB/3T3 cells (Bhas 42 cells), whereas it did not induce any growth of BALB/3T3 cells without $v$-Ha-ras gene, indicating that TNF- $\alpha$ is a tumor promoter or cancer mediator in tumor development [3].

In addition, treatment of BALB/3T3 cells with human TNF- $\alpha$ at a concentration of $10 \mathrm{ng} / \mathrm{ml}(0.6 \mathrm{nM})$ significantly induced 0.33 foci/dish, even without initiation of MCA, whereas MCA at concentration of $0.1 \mu \mathrm{g} / \mathrm{ml}(0.4 \mu \mathrm{M})$ alone showed 0.08 , and DMSO in medium was 0 [6]. Moreover, the clones from TNF- $\alpha$ transformed foci of BALB/3T3 cells showed strong tumorigenicity in sites of injected mice, and also induced expression of $I L-1 \alpha, I L-6$, and TGF- $\beta$ genes [15]. The results indicate that human TNF- $\alpha$ has both potent initiating and promoting activity.

\section{TNF- $\alpha$-inducing protein (Tip $\alpha)$ of $H$. pylori for gastric cancer progression}

If tumor promotion can be understood as up-regulated expression of TNF- $\alpha, I L-1$ and chemokinegenes thatare associated with activation of NF- $\kappa B$, tumor promotion significantly can be closed up to the stage of progression in human cancer development. In order to prove this concept, we studied a link between TNF- $\alpha$ and H. pylori infection with Helicobacter pylori membrane protein 1 (HP-MP1) isolated from $H$. pylori strain SR 7791 [16]. HP-MP1 induced release of various inflammatory cytokines, such as TNF- $\alpha$, IL- $1 \alpha$ and IL-8, and also macrophage inflammatory protein $1 \alpha$ from human monocytes, although HPMP1 is structurally unrelated to virulence factors such as cagA, vacA, and urease [16]. Next, HP-MP1 gene was transfected into $v$-Ha-ras-transfected BALB/3T3 cells (Bhas 42 cells, named Bhas/mpl) and v-Ha-ras-non-transformed BALB/ 3T3 cells (BALB/mp1), and clones of HP-MP1-transfected Bhas/ mpl cells induced TNF- $\alpha$ gene expression more strongly that did BALB/ mpl clones, and also induced cell transformation and tumors in nude mice [8].

In order to more broadly understand the function of $H P$ MP1 gene, we isolated HP0596 gene from H. pylori strain 26695, which was $94.5 \%$ homologous to HP-MP1 gene, and designated HP0596 protein as the TNF- $\alpha$-inducing protein (Tip $\alpha$ ) [11]. Tip $\alpha$ showed the same activity as did HP-MP1, and induced extensive expression of the chemokine genes, such as Ccl2, Ccl7, Cxcl1, Cxcl2, Cxcl5 and Cxcl10 in mouse gastric cancer cell line MGT-40 [17], while the inactive form of Tip $\alpha$ (del-Tip $\alpha$ has deletion of six amino acids containing two cysteine residues) showed only marginal expression. Since Tip $\alpha$ is produced in various $H$. pylori strains, the amount of Tip $\alpha$ in culture broth of H. pylori was determined depending on gastric ailment. H. pylori cultured from gastric cancer patients secreted Tip $\alpha$ at 1.4-13.4 relative units, and those from gastritis patients secreted at 0.8 6.7 relative units [11].

Like TNF- $\alpha$, IL-1 $\beta$ and IL-6 are critical mediators in tumorigenesis, and the stomach-specific expression of human IL-1 $\beta$ in transgene mice induced spontaneous gastric inflammation and cancer [18]. Since HP-MP1 (Tip $\alpha$ ) induced release of various inflammatory cytokines, such as TNF- $\alpha$ and IL-1 $\alpha$ from human monocytes [16], we conclude that pathologic elevation of a single pro-inflammatory cytokine is sufficient to induce cancer.

\section{Nucleolin on cell surface as a receptor for Tip $\alpha$}

Tip $\alpha$ binding protein was found in cell lysates of mouse gastric cancer cell line MGT-40 using FLAG-pulldown assay and was identified as cell surface nucleolin by LC-MS analysis and flow cytometry using anti-nucleolin antibody. Nucleolin was then co-precipitated with Tip $\alpha-F L A G$, but not with delTip $\alpha$-FLAG (an inactive mutant) [10]. The direct binding of Tip $\alpha$ to recombinant His-tagged nucleolin fragment (284-710) was also confirmed. Pretreatment with anti-nucleolin antibody enhanced Tip $\alpha$-incorporation into the cells through nucleolin internalization [10], indicating a new mechanistic insight into gastric cancer development with Tip $\alpha$. 
The rdel-Tip $\alpha$ protein is an inactive monomer, with biological activity 10-50 fold weaker than that of rTip $\alpha$. The crystal structure of rdel-Tip $\alpha$ was determined using Multiple Isomorphous Replacements with Anomalous Scattering (MIRAS) [19], since recombinant Tip $\alpha$ (rTip) did not grow to the crystal. The results suggest that rTip $\alpha$ is secreted from $H$. pylori as a soluble homodimer through a secretion mechanism different from the Type IV secretion system, because neither HP-MP1 nor rTip $\alpha$ has a hydrophobic surface that interacts with the lipid layer of the membrane [19].

\section{Epithelial-Mesenchymal Transition (EMT) in human gastric cancer cells by Tip $\alpha$}

Epithelial-Mesenchymal Transition (EMT) is theoretically understood as acquisition by epithelial cells of the phenotype of mesenchymal cells, such as fibroblasts. For example, cancer cells phenotypically are more likely to become mesenchymal cells associated with metastatic states, such as changes in cell shape and gene expression [20]. Tip $\alpha$ binding to surface nucleolin resulted in induction of the early metastatic states of cancer cells, such as migration, elongation and formation of filopodia associated with invasive changes in human gastric cancer cell line MKN-1, which were inhibited by the nucleolin-targeted siRNAs [12]. Tip $\alpha$ enhanced phosphorylation of 11 cancer-related proteins and activation of MEK-ERK signal cascade. It is of interest to note that Tip $\alpha$ reduced cell stiffness and increased cell motility, determined by atomic force microscopy. We think Tip $\alpha$ is a new inducer of EMT associated with tumor progression in human gastric carcinogenesis mediated through TNF- $\alpha$ [12].

\section{Discussion}

This review provided evidence that TNF- $\alpha$ and IL-1 are directly involved in tumor-promoting inflammation and progression. The secretion of pro-inflammatory cytokines, such as IL-1 $\beta$, and IL18 is mediated by cysteine protease caspase- 1 , IL-1 $\beta$-converting enzyme, in activation of inflammasomes [21]. Inflammasomes are large protein complexes (>700 $\mathrm{kDa}$ ) typically consisting of caspase-1, a Nucleotide Binding-Oligomerization Domain (Nod)-like Receptor (NLR), an adaptor protein apoptosisassociated speck-like protein containing a Caspase Activation and Recruitment Domain (Card) domain (ASC) [22], and play divergent roles in different types of cancer reflecting the complexity of inflammation [23]. As previously reported, both IL- $1 \alpha$ and IL-1 $\beta$ contribute to tumor angiogenesis and invasiveness, but the role of IL-1 $\beta$ is more evident in these processes [24]. In inflammatory cells, caspase- 1 activation can fuel a cycle that leads to sterile inflammation and carcinogenesis, whereas in antigen-presenting cells, inflammasomes can stimulate anticancer immune responses [25].

The results of Campanelli's group are worthwhile to note that the two-stage carcinogenesis experiments with DMBA and TPA induced the first tumor at the $5^{\text {th }}$ week on caspase-1(CASP)-1-KO mice, at the $7^{\text {th }}$ week on ASC-KO mice, and at the $10^{\text {th }}$ week on wild type mice, and that the levels of pro-inflammatory cytokinses, such as IL-1 $\beta$, IL-18 and TNF- $\alpha$ in the tumors from CASP-1-KO and ASC-KO mice decreased when compared with wild type mice, indicating that loss of inflammasome function enhanced the process of tumor development [13]. The results indicate that inflammasomes play dual roles in the control of cancer development [13].

\section{Acknowledgment}

This work was supported by Japan Society for the Promotion of Science, the Smoking Research Foundation, Tokushima Bunri University, the Urakami Foundation, and Grants-in Aid for Cancer Research: Special Cancer Research, from the Ministry of Education, Science, Sports and Culture, Japan, the Research on HTLV-1 Associated diseases from Saga Prefecture, Japan, and the Princess Takamatsu Cancer Research Fund.

\section{References}

1. Fujiki H, Hecker E, Moore RE, Sugimura T, Weinstein IB. Cellular Interaction by Enviromental Tumor Promoters. Tokyo/ Utrecht: Jap Sci Soc Press/ VNU Sci Press; 1983.

2. Fujiki $H$, Suganuma M. Tumor necrosis factor- $\alpha$, a new tumor promoter, engendered by biochemical studies of okadaic acid. J Biochem. 1994;115:1-5.

3. Suganuma M, Okabe S, Marino MW, Sakai A, Sueoka E, Fujiki H. Essential role of tumor necrosis factor $\alpha(\mathrm{TNF}-\alpha)$ in tumor promotion as revealed by TNF- $\alpha$-deficient mice. Cancer Res. 1999;59(18):45164518.

4. Fujiki H, Suganuma M. Tumor promotion by inhibitors of protein phosphatases 1 and 2A: the okadaic acid class of compounds. Adv Cancer Res. 1993;61:143-194.

5. Sueoka E, Sueoka N, Okabe S, Kozu T, Komori A, Ohta T, et al. Expression of the tumor necrosis factor $\alpha$ gene and early response genes by nodularin, a liver tumor promoter, in primary cultured rat hepatocytes. J Cancer Res Clin Oncol. 1997;123:413-419.

6. Komori A, Yatsunami J, Suganuma M, Okabe S, Abe S, Sakai A, et al. Tumor necrosis factor acts as a tumor promoter in BALB/3T3 cell transformation. Cancer Res. 1993;53:1982-1985.

7. Fujiki H, Sueoka E, Suganuma M. Tumor promoters: from chemicals to inflammatory proteins. J Cancer Res Clin Oncol. 2013;139(10):160314. doi: 10.1007/s00432-013-1455-8.

8. Suganuma M, Kurusu M, Okabe S, Sueoka N, Yoshida M, Wakatsuki $\mathrm{Y}$, et al. Helicobacter pylori membrane protein 1: a new carcinogenic factor of Helicobacter pylori. Cancer Res. 2001;61(17):6356-6359.

9. Suganuma M, Kurusu M, Suzuki K, Nishizono A, Murakami K, Fujioka $\mathrm{T}$, et al. New tumor necrosis factor-alpha-inducing protein released from Helicobacter pylori for gastric cancer progression. J Cancer Res Clin Oncol. 2005;131(5):305-313.

10. Watanabe T, Tsuge H, Imagawa T, Kise D, Hirano K, Beppu M, et al. Nucleolin as cell surface receptor for tumor necrosis factor- $\alpha$ inducing protein: a carcinogeic factor of of Helicobacter pylori. J Cancer Res Clin Oncol. 2010 Jun;136(6):911-21. doi: 10.1007/ s00432-009-0733-y.

11. Suganuma M, Yamaguchi K, Ono Y, Matsumoto H, Hayashi T, Ogawa $\mathrm{T}$, et al. TNF- $\alpha$-inducing protein, a carcinogenic factor secreted from H. pylori, enters gastric cancer cells. Int J Cancer. 2008;123:117-122.

12. Watanabe T, Takahashi A, Suzuki K, Kurusu-Kanno M, Yamaguchi K, Fujiki $\mathrm{H}$, et al. Epithelial-mesenchymal transition in human gastric 
cancer cell lines induced by TNF- $\alpha$-inducing protein of Helicobacter pylori. Int J Cancer. 2014;134(10):2373-82. doi: 10.1002/ijc.28582.

13. Gasparoto TH, de Oliveira CE, de Fraitas LT, Pinheiro CR, Hori JI, Garlet $\mathrm{GP}$, et al. Inflammasome activation is critical to the protective immune response during chemically induced squamouse cell carcinoma. PLoS One. 2014;9(9):e107170. doi: 10.1371/journal.pone.0107170.

14. Guy GR, Cao X, Chua SP, Tan YH. Okadaic acid mimics multiple changes in early protein phosphorylation and gene expression induced by tumor necrosis factor or interleukin-1. J Biol Chem. 1992;267(3):1846-52.

15. Suganuma M, Okabe S, Kurusu M, Iida N, Ohshima S, Saeki Y, et al. Discrete roles of cytokines, TNF- $\alpha$, IL-1, IL- 6 in tumor promotion and cell transformation. Int J Oncol. 2002;20(1):131-6.

16. Yoshida M, Wakatsuki Y, Kobayashi Y, Itoh T, Murakami K, Mizoguchi A, et al. Cloning and characterization of a novel membrane-associated antigenic protein of Helicobacter pylori. Infect Immun. 1999;67:286293.

17. Kuzuhara T, Suganuma M, Kurusu M, Fujiki H. Helicobacter pylorisecreting protein Tip $\alpha$ is a potent inducer of chemokine gene expressions in stomach cancer cells. J Cancer Res Clin Oncol. 2007;133:287-296.

18. Tu S, Bhagat G, Cui G, Takaishi S, Kurt-Jones EA, Rickman B, et al. Overexpression of interleukin-1 $\beta$ induces gastric inflammation and cancer and mobilizes myeloid-drived suppressor cells in mice. Cancer Cell. 2008;14(5):408-19. doi: 10.1016/j.ccr.2008.10.011.
19. Tsuge H, Tsurumura T, Utsunomiya H, Kise D, Kuzuhara T, Watanabe $\mathrm{T}$, et al. Structural basis for the Helicobacter pylori-carcinogenic TNF- $\alpha$-inducing protein. Biochem Biophys Res Commun. 2009;388(2):193-8. doi: 10.1016/j.bbrc.2009.07.121.

20. Polyak K, Weinberg RA. Transitions between epithelial and mesenchymal states: acquisition of malignant and stem cell traits. Nat Rev Cancer. 2009;9(4):265-73. doi: 10.1038/nrc2620.

21. Shurin MR. Dual role of immunomodulation by anticancer chemotherapy. Nat Med. 2013;19(1):20-22.

22. Martinon F, Burns K, Tschopp J. The inflammasome: a molecular platform triggering activation of inflammatory caspases and processing of proIL- $\beta$. Mol Cell. 2002; 10(2): 417-26.

23. Janowski AM, Kolb R, Zhang W, Sutterwala FS. Beneficial and detrimental roles of NLRs in carcinogenesis. Front Immunol. 2013 Nov 12;4:370. doi: 10.3389/fimmu.2013.00370.

24. Voronov E, Shouval DS, Krelin Y, Cagnano E, Benharroch D, Iwakura $Y$, et al. IL-1 is required for tumor invasiveness and angiogenesis. Proc Natl Acad Sci USA. 2003;100(5):2645-2650.

25.Zitvogel L, Kepp O, Galluzzi L, Kroemer G. Inflammasomes in carcinogenesis and anticancer immune responses. Nat Immunol. 2012;13(5):343-51. doi: 10.1038/ni.2224 